\title{
ANÁLISE DAS ESTRATÉGIAS METODOLÓGICAS E DISCURSIVAS DO DIAGNÓS- TICO SOCIOECONÔMICO NO ESTUDO DE IMPACTO AMBIENTAL DO PROJETO SANTA QUITÉRIA/CEARÁ
}

Resumo: Os marcos jurídicos que conformam os Estudos de Impactos Ambientais imprimem a obrigatoriedade dos diagnósticos socioeconômicos do meio em que o empreendimento se insere. Esta pesquisa consiste em investigar as informações e metodologias que compõem o diagnóstico realizado pelo EIA do Projeto Santa Quitéria/CE, observando quais dimensões foram privilegiadas, a base de dados utilizada, a definição das áreas atingidas e o contraste com a percepção dos sujeitos atingidos. Na metodologia, utiliza-se revisão de literatura, análise documental e observação participante. Nos resultados, pontua-se que a consultoria caracterizou o território sob uma ótica distanciada de suas experiências sociais, viciando o rito ambiental.

Palavra-chave: Estudo de Impacto Ambiental; Diagnóstico socioeconômico; Projeto de mineração Santa Quitéria/CE; Discursos ambientais; Áreas Diretamente Atingidas;

\section{ANALYSIS OF THE METHODOLOGICAL AND DISCURSIVE STRATEGIES OF THE SOCIOECONOMIC DIAGNOSIS IN THE ENVIRONMENTAL IMPACT STUDY OF THE SANTA QUITÉRIA/CEARÁ PROJECT}

\begin{abstract}
The legal frameworks that accommodate the Environmental Impact Assessment Studies transmit the socioeconomic obligation of the environment that the enterprise is situated. This research consists in investigating the information and methodologies on the EIA diagnostic on the Santa Quitéria/CE project, looking at which dimensions were prioritized, the data based used, the definition of areas and the contrast with the perception of approached Persons In the methodolo-

\footnotetext{
${ }^{1}$ Doutoranda em Direito pela Universidade de Brasília. Mestre em Direito pela Universidade Federal do Ceará. Membro do grupo de pesquisa Núcleo Tramas/UFC - Trabalho, Saúde e Sustentabilidade e do Instituto de Pesquisa Direito e Movimentos Sociais - IPDMS.
}

Revista de Direito Ambiental e Socioambientalismo | e-ISSN: 2525-9628 | Brasília | v. 3 | n. 1 | p. 40 60 | Jan/Jun. 2017. 


\section{Análise das estratégias metodológicas e discursivas do diagnóstico socioeconômico no}

estudo de impacto ambiental do projeto Santa Quitéria/Ceará

gy is used a review of the literature, documentary analysis, and participation observation. In the results, it is pointed out that consulting the territory under a distant view about their social experience, addicting the environmental habit.

Key words: Environmental Impact Study; Socioeconomic diagnosis; Santa Quitéria - CE Mining Project; Environmetal discourses; Directly affected áreas.

\section{INTRODUÇÃ̃O}

A partir da Constituição de 1988 e a fundamentalização do direito ao ambiente, aponta-se para existência de uma ordem constitucional ambiental, marcada pela supremacia dos valores constitucionais e o fenômeno da "ecologização da constituição brasileira", concluindo pela "substituição do paradigma da legalidade ambiental pelo paradigma da constitucionalidade ambiental"' (CANOTILHO, 2008, p.4).

Neste sentido, existiria um Estado de Direito Ambiental, como um novo paradigma constitucional que redimensiona a compreensão sobre o meio ambiente, conferindo-lhe proeminência. Antonio Benjamin (2008, p. 67) destaca como característica deste modelo a preocupação com a implementação de suas normas, trazendo instrumentos e deveres de cumprimento da tutela ambiental no próprio texto constitucional.

Destes instrumentos, encontra-se a avaliação de impacto ambiental, instrumento da Política Nacional de Meio Ambiente, conduzida por procedimentos administrativos e estudos ambientais, dentre os quais se destaca o Estudo de Impacto Ambiental - EIA. Alexandra Aragão (2011) aponta o histórico normativo europeu acerca do dever de prevenção de riscos, inicialmente para gestão de riscos industriais. Merece destaque a Convenção de Espoo de 1991, que instituiu o procedimento de avaliação de impactos ambientais transfronteiriços, válida no âmbito das nações unidas para a Europa, fixando padrões internacionais do procedimento de avaliação de riscos, estabelecendo que ela seja aberta ao público e participativo; que considere a hipótese zero, ou seja, a de não realização da intervenção e que as decisões ambientais sejam amplamente motivadas.

\section{Revista de Direito Ambiental e Socioambientalismo | e-ISSN: 2525-9628 | Brasília | v. 3 | n. 1 | p. 40 -} 60 | Jan/Jun. 2017. 
No direito interno, a avaliação de impactos de empreendimentos potencialmente lesivos ao ambiente foi positivada como um instrumento Lei n ${ }^{\circ} 6.938$ - Política Nacional do Meio Ambiente - de 1981, regulamentada pelo Decreto n 88.351 de 1983 e, ainda, pelas Resoluções do Conselho Nacional do Meio Ambiente - CONAMA.

A Constituição assegurou a tutela ambiental por meio de seu artigo 225, com referência expressa ao Estudo Prévio de Impacto Ambiental, por meio do qual a avaliação de impactos brasileira objetiva realizar um procedimento público e cientificamente subsidiado que dê todas as informações necessárias para analisar a viabilidade socioambiental de qualquer intervenção potencialmente lesiva ao ambiente. Já o licenciamento consiste em um procedimento administrativo que identificará os requisitos e possibilidade de concessão ou não da licença ambiental, que se subdivide em três: Licença Prévia (LP), Licença de Instalação (LI) e Licença de Operação (LO).

O estudo ambiental é delimitado por um conteúdo mínimo, devendo conter levantamento da literatura científica e jurídica sobre o assunto; delimitar a área de influência do projeto e as áreas atingidas (tomando como critério a bacia hidrográfica); considerar os planos, programas e zoneamento da região; confrontar o projeto com suas alternativas técnicas, locacionais e não realização; identificar e analisar os impactos em todas as fases; propor medidas mitigadoras e programas de monitoramento e, notoriamente o que interessa a esta pesquisa, realizar a descrição do meio socioeconômico (CONAMA, Resolução 01/86, artigo 6 $6^{\circ}$, inciso I, alínea c).

Dito isto, salienta-se que esta pesquisa reflete o resultado de um estudo empírico sobre a caracterização social desenvolvida no EIA do Projeto de mineração de urânio e fosfato Santa Quitéria/CE. Objetiva-se investigar, a partir de estudos de caso, como os estudos ambientais brasileiros caracterizam as comunidades campesinas atingidas por projetos classificados como de "desenvolvimento".

A proposta da pesquisa avança na medida em que procura não apenas diagnosticar o problema, mas apontar as estratégias discursivas pelas quais ele se materializa, contribuindo para que os pesquisadores e operadores jurídicos possam perceber similaridades, contestar ou refutar os resultados do estudo empírico.

Para isto, compreende-se o discurso como a "expressão particular da estrutura das relações de força entre os grupos que possuem as competências correspondentes" (BOURDIEU, 


\section{Análise das estratégias metodológicas e discursivas do diagnóstico socioeconômico no estudo de impacto ambiental do projeto Santa Quitéria/Ceará}

1977, p.3). As idéias embutidas nas falas e o formato dos espaços públicos de debate se associam dentro das estratégias de produção da aceitação social.

O discurso positivo a respeito dos empreendimentos tem sua eficácia atrelada aos contextos rituais de sua enunciação e não pode funcionar independente deles. O discurso e a palavra não são dissociáveis do ritual, em que os sujeitos falantes e seus enunciados adquirem eficácia. (BRONZ, 2011, p.162) (grifo nosso)

Adentrando na metodologia utilizada, vale frisar os aportes que destacam o papel de um olhar disciplinado sobre o campo social (CARODOSO, 1996), que utiliza dos conhecimentos disciplinares reconhecendo as interferências e refrações exercidas sobre os dados. Não se trata de uma pesquisa etnográfica, mas foram utilizadas técnicas de pesquisa etnográficas (ROCHA, ECKERT), no esforço para manter o "olhar de perto e de dentro" (MAGNANI, 2002), um olhar que evita generalizar avaliações, hierarquizar saberes, desconhecer, preconceber ou homogeneizar as perspectivas, sujeitos e seus discursos.

A pesquisa utilizou os seguintes procedimentos metodológicos: revisão de literatura; análise documental e a observação participante, que ocorre a partir de uma presença regular do pesquisador na realidade em que imerge, com um convívio que permita extrair discursos, valores, códigos, intenções, sentidos, estratégias das vivências dos sujeitos com o qual interage (ROCHA, ECKERT, 2008, p.6). O período de campo da pesquisa desenvolveu-se em dez encontros de maio de 2014 a janeiro de 2015. Tais encontros foram antecedidos por uma aproximação prévia com o campo de pesquisa diante da participação no Núcleo Tramas/UFC, grupo de pesquisa que desde 2010 realiza atividades na região, e do Painel Acadêmico Popular, um grupo de pesquisadores que se articularam em torno da análise do Estudo de Impacto Ambiental do projeto em 2014.

Para cumprir o propósito investigativo, o trabalho irá apresentar uma imersão sobre o que é o Projeto Santa Quitéria; posteriormente, realiza-se uma análise sobre a caracterização dos sujeitos sociais, a forma de definição da área atingida e os discursos utilizados pela consultoria ambiental na caracterização da região para, em vias de considerações finais, apontar os resultados do estudo empírico.

\section{O PROJETO DE MINERAÇÃO SANTA QUITÉRIA}

Revista de Direito Ambiental e Socioambientalismo | e-ISSN: 2525-9628 | Brasília | v. 3 | n. 1 | p. 40 60 | Jan/Jun. 2017. 
A política econômica do Estado do Ceará insere-se no contexto do neodesenvolvimentismo (SAMPAIO JR, 2012) associado ao neoextrativismo (MILANEZ \& SANTOS, 2013) que têm em comum a ideia de progresso como crescimento ilimitado, sob o qual se justificam as apropriações dos bens ambientais e a concepção de que Estado e mercado consistem em esferas complementares para geração do crescimento econômico impulsionado por grandes empreendimentos.

Este modelo encontra amparo na noção hegemônica de desenvolvimento que Raquel Rigotto, com aporte em Castoriadis, caracteriza como uma concepção de "desenvolvimento como crescimento ilimitado da produção e das forças produtivas [que] é, de fato, o objetivo central da vida humana. Desenvolvimento é a progressão em direção à maturidade, à capacidade de crescer sem fim, colocada como natural” (RIGOTTO, 2004, p.77).

A narrativa do desenvolvimento se cruza com outras que lhe são irmanadas, tais como a de progresso e crescimento. Por meio de diferentes estratégias de sua afirmação, a noção funciona como legitimadora de grandes projetos, a exemplo do Projeto de mineração de urânio e fosfato Santa Quitéria. Enquanto aparato justificativo, o desenvolvimento apresenta-se como doxa (BOURDIEU, 1977; CARNEIRO, 2005) entendida como o "conjunto de pressupostos que os antagonistas admitem como sendo evidentes, aquém de qualquer discussão, porque constituem a condição tácita da discussão" (BOURDIEU, 1977, p.113).

Tais empreendimentos geram e/ou acirram os chamados conflitos ambientais (ACSERALD, 2014, ZHOURI \& LASCHEFSKI, 2010). A literatura aponta a recorrência destes conflitos e, no Ceará, merece destaque o caso do agronegócio na Chapada do Apodi (RIGOTTO et al, 2011), do Projeto de mineração de urânio e fosfato Santa Quitéria (MELO, 2015; MONTEZUMA 2015) e da carcinicultura em territórios quilombolas (MEIRELES et al, 2014).

A jazida mineral Itataia, situada entre os municípios de Santa Quitéria (CE) e Itatira (CE), a aproximadamente $210 \mathrm{~km}$ de Fortaleza, foi "descoberta" em 1976, fase em que o governo ditatorial buscava as "riquezas" das nossas terras ${ }^{2}$. Por meio de pesquisas realizadas pelas Empresas Nucleares Brasileiras S/A (Nuclebrás), revelou-se alta quantidade do minério

\footnotetext{
${ }^{2}$ Informações obtidas em < http://www.funeri.jex.com.br/meio+ambiente+no+mundo/santa+quiteria+reabre+mina ,
} pesquisa realizada em 18.20.08.

Revista de Direito Ambiental e Socioambientalismo | e-ISSN: 2525-9628 | Brasília | v. 3 | n. 1 | p. 40 60 | Jan/Jun. 2017. 
colofanito, que consiste na associação de urânio, cujo destino seria alimentar a matriz energética nuclear, e o fosfato destinado para a produção de fertilizantes agrícolas (ARCADIS LOGOS, 2014, V.1, p. 11).

DE acordo com o EIA do projeto, trata-se da maior reserva de urânio do país, que está localizada em uma área de 4.001,04 hectares, de titularidade da Indústrias Nucleares do Brasil INB (ARCADIS LOGOS, 2014,vol. I , p. 134). Em 1990, a empresa estatal Nuclebrás, hoje Indústrias Nucleares do Brasil - INB, reiniciou a pesquisa mineral na área, após autorização de pesquisa concedida pelo Departamento Nacional de Produção Mineral - DNPM. Após a autorização de pesquisa, o projeto obteve Portaria de Lavra emitida pelo DNPM em 03.10.2005, no interior do processo administrativo $\mathrm{n}^{\circ} 800.095 / 1990^{3}$. Desde então, são empreendidos esforços para obter a licença ambiental do projeto (ARCADIS LOGOS, 2014, v.1, p.126).

De início, o licenciamento foi proposto no âmbito do órgão ambiental estadual, ocasião em que chegou a ser concedida a Licença Ambiental Prévia nº 1413/04 e a Licença de Instalação n. $^{\text { }}$ 2164/04 $4^{4}$, que autorizaram a atividade de extração de urânio e ácido fosfórico no empreendimento denominado “Complexo Industrial de Santa Quitéria”.

O Ministério Público Federal - MPF, entretanto, detectou ilegalidades ${ }^{5}$ no licenciamento e solicitou, judicialmente, a anulação das licenças concedidas, o que foi obtido por meio da Ação Civil Pública no . 2005.81.00.013905-6. Em 2009 é firmado o contrato do atual "Consórcio Santa Quitéria”, composto pelas empresas INB, empresa pública que detém o monopólio de atuação na área nuclear, e o grupo privado Galvani Indústria, Comércio e Serviço S.A, que atua na produção de fertilizantes. O consórcio é, portanto, o empreendedor do projeto.

\footnotetext{
${ }^{3}$ Junto a este processo principal de concessão de lavra no DNPM se encontram vinculados os processos 800.853/76, 810.789/76, 810.791/76 e 800.095/90 (ARCADIS LOGOS, 2014, v.1, p.140).

${ }^{4}$ Vale destacar que, entre a concessão da Licença Prévia e a concessão da Licença de instalação decorram-se apenas 7 dias, prazo insuficiente para elaboração do Projeto Básico Ambiental e para o cumprimento das condicionantes. Ademais, na época, a Semace não realizou audiências públicas para discussão do projeto.

${ }^{5} \mathrm{Na}$ época, em relatório de vistoria, o Ibama apontou inadequações no EIA/RIMA, tais como a ausência de consulta ao Instituto do Patrimônio Histórico e Artístico Nacional - IPHAN, de informações sobre aspectos culturais, de lazer e de turismo das comunidades próximas ao empreendimento, problemas na delimitação da Área de Influência Indireta, a não identificação de lideranças sociais locais e a não realização de Estudo de Análise de Riscos. Informações constam no Ofício 1051/2012/DILIC/IBAMA.
} 
Em 2012, o consórcio apresentou um estudo que não foi previamente aceito pelo órgão ambiental, por não atender aos requisitos estabelecidos no Termo de Referência ${ }^{6}$. Em abril de 2014, a empresa de consultoria ARCADIS Logos $\mathrm{Ltda}^{7}$, apresenta novo EIA, desta vez acolhido pelo Ibama. Em novembro de 2014, foram realizadas três audiências públicas para discutir o projeto que, atualmente, aguarda parecer técnico final do IBAMA.

Durante as audiências, diversas comunidades, entidades e movimentos sociais participaram da discussão sobre o projeto, protocolizando inúmeros documentos em que questionavam insuficiências do EIA.

Dentre os questionamentos, estão os impactos para a saúde humana decorrente da dispersão de materiais radioativos, os riscos de contaminação ambiental, a desestruturação do modo de vida local, as insuficiências do estudo ambiental e a ausência de viabilidade hídrica. Vale destacar que, ao tempo em que as comunidades do entorno vivenciam três anos consecutivos de escassez de água, para o empreendimento será construída uma adutora de água no valor de R $\$$ 85 milhões que estima consumir o equivalente a 911.800 litros/hora (ARCADIS LOGOS, 2014, V.1, p.242), o que corresponde a aproximadamente 125 carros-pipa por hora ${ }^{8}$.

\section{A CARACTERIZAÇÃO SOCIAL REALIZADA NA ANÁLISE AMBIENTAL}

O projeto se situa no município de Santa Quitéria, no sertão central cearense e, geograficamente, fica perto das divisas com Itatira e Canindé, outros dois municípios do entorno.

\footnotetext{
${ }^{6}$ Informação prestada verbalmente durante as audiências públicas do licenciamento ambiental do projeto, ocorridas nos dias 20, 21 e 22 de novembro de 2015.

${ }^{7}$ A empresa de consultoria ambiental possui sede em São Paulo e se encontra registrada sob o número de CNPJ 61.371.852/0001-80. Resultado da incorporação de outras quatro empresas, controlada pela a ARCADIS NV, companhia global fundada na Holanda em 1888, a empresa afirma ter atuação no mercado nacional desde a década de 1970 e consistir em um dos cinco maiores grupos de engenharia do mundo. Em seu site, a apresenta se apresenta como "Habilitada para oferecer uma vasta gama de serviços e soluções adaptadas a empresas de todos os portes e naturezas - do pequeno ao grande, do simples ao complexo - a ARCADIS Logos atua em todas as etapas de Projetos de Engenharia, da fase inicial de Concepção e Estudos Ambientais até a Implementação Efetiva e operações." Informações obtidas em < http://www.arcadislogos.com.br/novo/pt-br/>, acesso realizado em 18.08.2015.

${ }^{8}$ Consideramos um carro pipa que comporte 8 mil litros de água, sendo este o padrão utilizado para abastecimento das comunidades de Morrinhos e Riacho das Pedras, conforme nos foi informado pelos moradores durante a realização da pesquisa de campo.
} 


\section{Análise das estratégias metodológicas e discursivas do diagnóstico socioeconômico no estudo de impacto ambiental do projeto Santa Quitéria/Ceará}

De acordo com os resultados de pesquisa de pós-doutorado desenvolvida no Núcleo Tramas ${ }^{9}$, pelo menos quarenta e duas comunidades, apenas dos municípios de Santa Quitéria e Itatira devem ser atingidas pelo empreendimento, dentre as quais destacamos as mais próximas à jazida, como o assentamentos de Morrinhos, Riachos das pedras, Lisieux, Alegre de Tatajuba e Saco de Belém.

Segundo os dados do Instituto Nacional de Cidadania e Reforma Agrária - INCRA e do Instituto do Desenvolvimento Agrário do Ceará - IDACE, existem vinte e três assentamentos rurais federais (com 1.287 famílias) e seis assentamentos rurais estaduais (com 188 famílias) em Santa Quitéria, além dos quatro assentamentos federais (com 198 famílias) de Itatira. (INCRA, online, 2015; IDACE, online, 2015). Existe um quadro complexo de negação de direitos sociais básicos a estas comunidades que se acentua pela ausência de políticas públicas que garantam condições sanitárias e ambientais de vida, acesso à água, estímulo à produção agrícola e ao modo de vida local, infraestrutura pública e assistência à saúde.

Entretanto, pulsa vida e diversidade nestes territórios, que não se caracterizam por um sentido de "ausências" ou "carências". Realizada a pesquisa, constatam-se múltiplos sentidos atribuídos aos territórios pelos moradores, com a valorização da agricultura camponesa, dos vínculos de vizinhança, da luta que empreenderam pela escolarização dos jovens, do histórico de luta pela terra e a conquista dos assentamentos. Outra dimensão que chama atenção é a diversidade cultural e produtiva, destacando-se as festas das comunidades, as experiências com redes de sementes crioulas, projetos de quintais produtivos, biocompostagens, estratégias de convivência hídrica com o semiárido, entre outros componentes do campesinato como "uma categoria histórica ou sujeito social, representando uma forma de manejar os recursos naturais vinculados aos agroecossistemas locais e específicos de cada zona" (SILVA, 2014, p.58).

\footnotetext{
${ }^{9}$ Informações retiradas do Relatório técnico-científico e de atividades consolidado do período já executado referente a projeto Prodoc/Edital 2010, coordenado pela profa. Dra. Raquel Maria Rigotto, projeto "Territorialização em Saúde: estudo das relações produção, ambiente, saúde e cultura na atenção primária ä saúde". O Núcleo Tramas Trabalho, Saúde e Ambiente, é um grupo de pesquisa interdisciplinar da Universidade Federal do Ceará que desenvolve pesquisas na região desde 2010. Pautado pelos princípios de uma ciência emancipatória, o grupo atua nas dimensões da produção de conhecimento, inserção social e formação.
} 
Por sua vez, o EIA do projeto, em atendimento às exigências do Termo de Referência, fez um diagnóstico social e elaborou uma Matriz de Atores Sociais. O campo realizado para este diagnóstico foi feito em 2011, nos períodos de 13 a 17 de junho e de 15 a 19 de agosto. Para tanto, a empresa de consultoria visitou as sedes dos municípios de Canindé, Santa Quitéria, Itatira e Madalena, além das comunidades de Riacho das Pedras, assentamento Queimadas, assentamento Morrinhos e o distrito de Lagoa do Mato (ARCADIS LOGOS, 2014, v.3, p.526). Assentamentos próximos à jazida como o de Saco do Belém, o maior da região, sequer foram visitados - tampouco incluso na análise dos impactos do projeto.

Chama atenção o curto período de tempo em que a consultoria realizou este diagnóstico e entrevistas, totalizando dois encontros de quatro dias. Ademais, deve-se considerar a hipótese de que a percepção dos sujeitos sociais possa ter sofrido transformações de 2011 até 2014 (conclusão do estudo), considerando a dinâmica de relações sociais, informações, debates e reflexões sobre o projeto.

A consultoria elaborou um cenário dos atores sociais envolvidos no conflito, que se manifesta pela figura abaixo:

Figura 1: Cenário dos Atores Sociais.

\section{Revista de Direito Ambiental e Socioambientalismo | e-ISSN: 2525-9628 | Brasília | v. 3 | n. 1 | p. 40 - 60 | Jan/Jun. 2017.




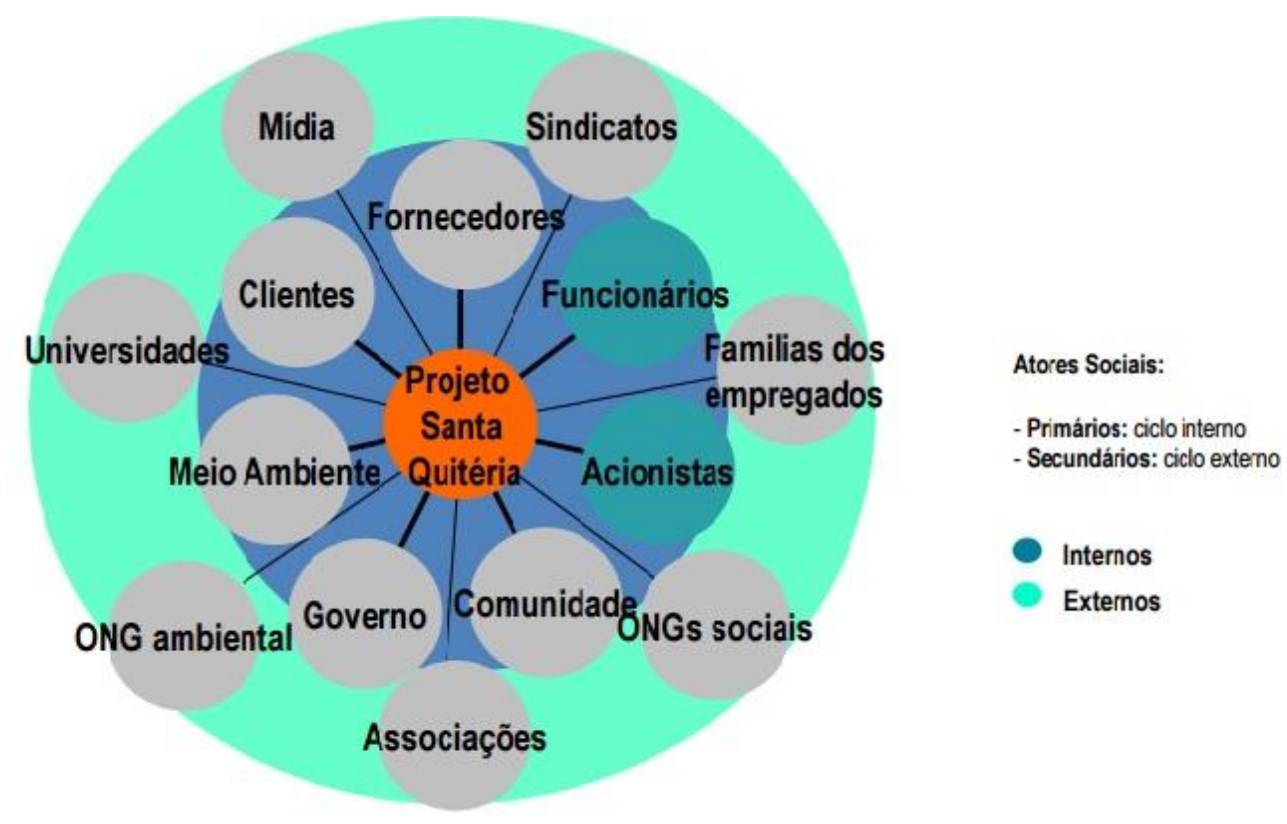

Figura 7.3-31 - Cenário de Atores Sociais Intervenientes ao Projeto Santa Quitéria

Fonte: ARCADIS LOGOS, 2014, v.3, p.528.

Para selecionar quais atores deveriam ser entrevistados, a consultoria desenvolveu critérios que consideravam o grau de relevância e o grau de potencial parceria com o empreendimento (ARCADIS LOGOS, 2014, v.3, p. 528). Os critérios foram sintetizados pela figura abaixo:

Revista de Direito Ambiental e Socioambientalismo | e-ISSN: 2525-9628 | Brasília | v. 3 | n. 1 | p. 40 60 | Jan/Jun. 2017. 
Figura 2: Grau de relevância dos atores sociais de acordo com o estudo ambiental.

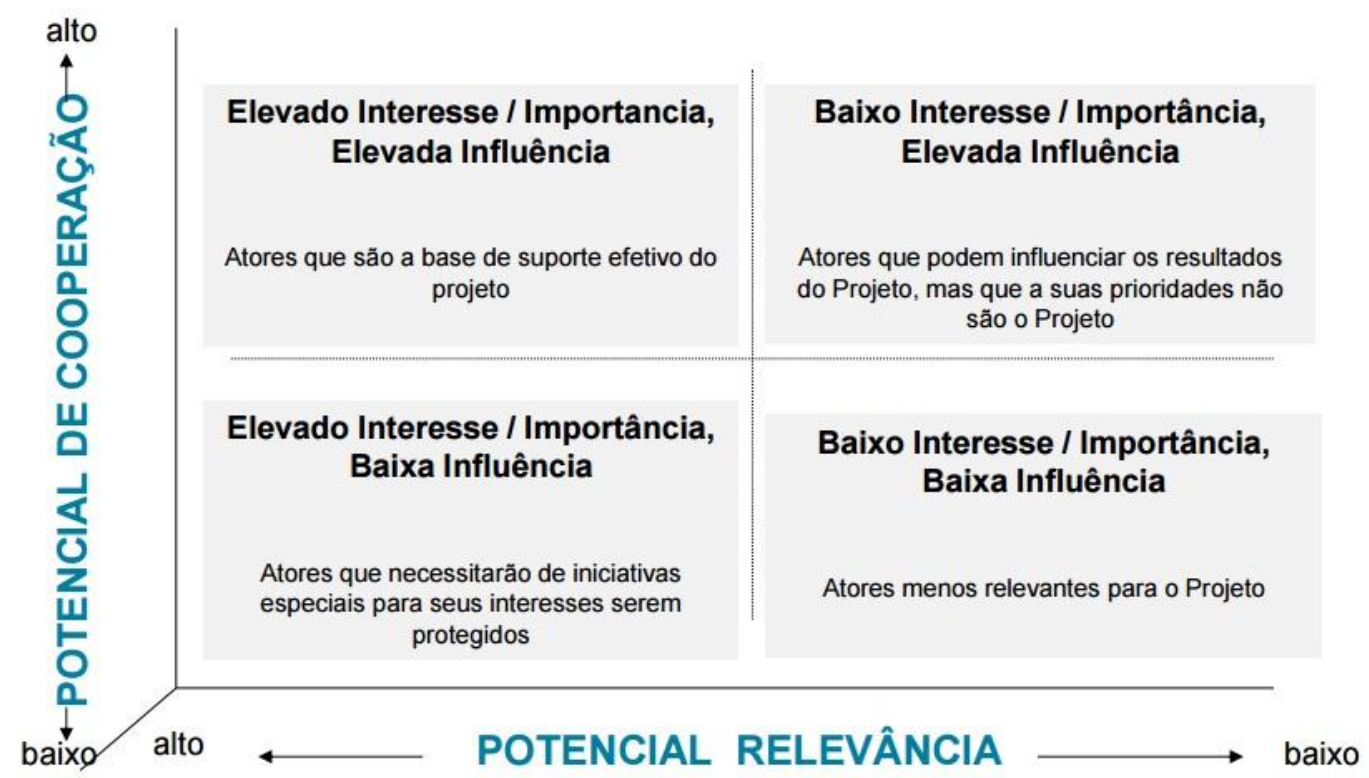

Figura 7.3-32 - Grau de relevância dos atores sociais em relação ao objeto de estudo

Fonte: ARCADIS LOGOS, 2014, v.3, p.529.

Os critérios "relevância" e "cooperação" informam sobre o método de elaboração de estudo e provocam distintos questionamentos. Para a consultoria, a relevância foi aferida pela capacidade de influência sobre o projeto, pelo nível de organização e coesão dos atores sociais e pelo critério daqueles atores que "dão a base de suporte efetivo do projeto".

Lançando um olhar crítico sobre o método de categorização dos sujeitos sociais, cumpre registrar a importância das comunidades e sujeitos sociais julgadas como pouco organizados, não sendo a inexistência de associações ou outros mecanismos formais um retrato fiel da coesão social do grupo. Vínculos comunitários e territoriais garantem a coesão social às vezes de forma mais eficaz do que a existência de aparelhos tradicionais de organização civil. A caracterização também não considerou a importância de comunidades e assentamentos atingidos e que não estão no perímetro da área de influência direta do projeto, outro equívoco do diagnóstico. 
O nível de cooperação com o projeto também não parece um critério adequado, principalmente para refletir sobre os possíveis conflitos sociais. A valorização do dissenso e da crítica, a compreensão dos pontos de contestação do empreendimento, constituem ferramentas úteis para análise dos conflitos que não podem ser desprezadas.

O resultado destes critérios foi um diagnóstico social conduzido por dados secundários e a realização de poucas entrevistas. Destas entrevistas, seis foram em Santa Quitéria, das quais cinco foram com o poder público municipal. Em Itatira, das cinco entrevistas, todas foram também com secretários municipais e com o vice prefeito. Fora do campo institucional, a consultoria apenas realizou uma entrevista com o ex-presidente da associação comunitária de Morrinhos, com os presidentes das associações comunitárias de Riacho das Pedras e Queimadas e com o representante da ONG Cactus, que atua na região. Da Articulação Antinuclear do Ceará, nenhuma entidade ou movimento foi procurada para as entrevistas, embora a consultoria conheça e mencione a existência das organizações como a Cáritas Diocesana, do Movimento dos Trabalhadores Sem Terra, do Núcleo Tramas/UFC e, em alguns momentos, insinua uma "influência" que exerceriam sob as comunidades sem, contudo, ouvi-los acerca das impressões sobre o projeto.

A análise dos atores e do conflito social feita desta forma implica em erros metodológicos que podem distorcer a realidade. A escuta de apenas um morador por comunidade, por exemplo, não permite que se compreenda a heterogeneidade de perspectivas internas. Além disso, de acordo com o EIA, todas as comunidades levantaram a ausência de informações mais precisas sobre o empreendimento.

Afora estes aspectos metodológicos, chama atenção a narrativa assumida pela consultoria ambiental no que se refere à caracterização da região. Ao tratar sobre a percepção das comunidades, que disseram não ter opinião formada ou não concordar com o projeto, a consultoria afirma no EIA que "essas posições se dão devido à ausência de informações acerca do projeto em estudo, uma vez que foi unânime nas entrevistas a solicitação de ações de comunicação social” (ARCADIS LOGOS, 2014, v.3, p.574). Posturas crítica ao projeto são, portanto, desqualificadas como sinônimo de falta de informação. 
Ainda na construção da percepção sobre a realidade social, observa-se que o EIA do projeto adentra em uma caracterização do empreendimento como oportunidade e "salvação" para a região.

A idéia de desenvolvimento é apresentada como salvação para os territórios "pobres", "miseráveis", "sem alternativas de crescimento", apoiada sob uma territorialidade urbanoabstrata $^{10}$, baseada na desqualificação da territorialidade vivida localmente. Existe, portanto, nos conflitos ambientais, um choque entre formas de apropriação espacial, decorrentes da expansão do processo de acumulação capitalista, que gera demanda de incorporação de novos recursos naturais, rivalisando com "outras formas de apropriação social das condições naturais, seja para fins de produção de valores de uso [...] ou identidade territorial de determinadas populações e comunidades" (CARNEIRO, 2005, p.29).

"Itataia revolucionará a economia dos sertões",", anuncia a manchete de um jornal local ao divulgar um dos seminários de apresentação do empreendimento. No evento ${ }^{12}$, realizado em Canindé, um deputado federal cearense caracterizou o local como uma "região fadada a viver numa miséria extrema sem alternativa"; por sua vez, a representante do Consórcio empreendedor responsável pela explicação do princípio da sustentabilidade e do plano de comunicação com as comunidades, afirmou que as preocupações com os impactos da mineração seriam "fruto da ignorância e do imaginário da população local”.

Nas audiências públicas do projeto, a consultoria ambiental concluiu sua apresentação afirmando que "a equipe considera que sim, de fato o empreendimento é uma oportunidade de melhorias".

A caracterização da região como um local "carente" se reforça pelas idéias de pobreza e atraso. O local significa o atraso enquanto que o industrial significa o moderno. A idéia de atraso, fruto de uma racionalidade que abrevia o mundo para universalizar seus próprios princípios, foi

\footnotetext{
${ }^{10}$ Para Harvey, o novo empreendedorismo urbano após a década de 70 "se apóia na parceria público-privada, enfocando o investimento e o desenvolvimento econômico, por meio da construção especulativa do lugar em vez da melhoria das condições num território específico, enquanto seu objetivo econômico imediato (ainda que não exclusivo)" (HARVEY, 2005, p. 167/174).

${ }^{11} \mathrm{http}: / /$ www.oestadoce.com.br/noticia/itataia-revolucionara-economia-dos-sertoes

${ }^{12}$ O seminário "Retomada do projeto de exploração da mina de Itataia e sua importância econômica para o Ceará", realizado em 11 de outubro de 2013, no município de Canindé, objetivava reunir representantes do Consórcio, deputados estaduais e federais com o poder público local, representado por vereadores e prefeitos dos municípios do entorno. As falas mencionadas foram transcrita do áudio do evento.
}

Revista de Direito Ambiental e Socioambientalismo | e-ISSN: 2525-9628 | Brasília | v. 3 | n. 1 | p. 40 60 | Jan/Jun. 2017. 


\section{Análise das estratégias metodológicas e discursivas do diagnóstico socioeconômico no estudo de impacto ambiental do projeto Santa Quitéria/Ceará}

viabilizada pela compressão da idéia de tempo presente em nome de uma expectativa expandida com o futuro. "Com isto, o que é considerado contemporâneo é uma parte extremamente reduzida do simultâneo" (SANTOS, 2010, p.100), que se reflete exatamente no olhar que não identifica no trabalho camponês a sua contemporaneidade, enquadrando-o como de outro tempo, aniquilando sua sobrevivência no presente. Para Boaventura de Sousa Santos, esta não contemporaneização contém uma assimetria que "esconde uma hierarquia, a superioridade de quem estabelece o tempo que determina a contemporaneidade" (SANTOS, 2010, p.100), terminando por reduzir a riqueza de experiências sociais do mundo.

Os grandes projetos de desenvolvimento vêm gerando um padrão de reordenamento espacial a partir de profundas interferências territoriais que se baseiam em critérios externos ao modo de vida local, e se inserem na lógica que se denomina por "geopolítica empresarial de gestão dos territórios". Nela, empreendedores e consultores vêm assumindo o protagonismo no ordenamento territorial, na medida em que passam a implementar seus projetos e instrumentos de "gestão" do território, atuando diretamente no gerenciamento dos efeitos das atividades empresariais sobre as populações, tendo no licenciamento ambiental um dos principais instrumentos de racionalização ${ }^{13}$ e oficialização dos programas de transformação territorial (BRONZ, 2011, p.172).

No EIA, a consultoria apresenta um diagnóstico social matematizado, ou seja, que explora dados numéricos, estatísticas, informações quantitativas que pouco acolhem as perspectivas e vivências dos sujeitos sociais ${ }^{14}$. As informações contidas no diagnóstico basicamente dizem respeito ao número de famílias, a composição social por faixa etária e gênero, ao índice da

\footnotetext{
13“"As idéias fora do lugar" e o "lugar fora das idéias" nos ajuda a compreender como a inflação de planos de ordenação territorial urbana não necessariamente implicaram em um aumento da qualidade de vida da população ou, tampouco, no direcionamento ordenado das cidades, uma vez que: a lógica de mercado prevalece sobre as lógicas , mercado formal e informal, são pensados fora do contexto. é urbano mas tem a ver (ARANTES, VAINER, MARICATO, 2000).

${ }^{14}$ Conforme apontamos na Introdução da pesquisa, o estudo faz inúmeras referências a dados secundários obtidos pelo IBGE e, nas entrevistas realizadas, enfatiza na percepção de funcionários municipais, trazendo entrevistas de representantes de apenas três comunidades da região. Nas entrevistas, valoriza-se identificar a percepção dos sujeitos sobre o projeto, suas preocupações, os benefícios que serão provocados e saber se existe um posicionamento formado. Pouco é estudado sobre a história das comunidades, a relação com a região, o histórico dos vínculos sociais e, fundamentalmente, poucas inter-relações são construídas entre as dimensões ambientais e sociais.
}

Revista de Direito Ambiental e Socioambientalismo | e-ISSN: 2525-9628 | Brasília | v. 3 | n. 1 | p. 40 60 | Jan/Jun. 2017. 
população economicamente ativa, a perspectiva de crescimento demográfico e aos comparativos de migração, seguindo orientações do Termo de Referência elaborado pelo Ibama. Os projetos comunitários desenvolvidos, os vínculos com o ambiente, a memória e a vizinhança, são exemplos das dimensões da caracterização social que não foram privilegiadas no estudo.

Neste cenário, opera-se um processo de desqualificação do modo de vida local, exemplificado por alguns trechos do estudo ambiental:

\begin{abstract}
A pirâmide etária de 2000 do Município de Canindé é uma pirâmide jovem ou crescente, pois possui a base larga e o topo estreito, típica de regiões com pouco desenvolvimento, pois apresenta taxa de natalidade elevada e baixa esperança média de vida. (ARCADIS LOGOS, 2014, v.3, p.26) [...]

.... a condição de pobreza dos municípios é evidenciada também pela ausência de dotações de desenvolvimento agrário e pastoril. (EIA, VOLUME III, p. 243). [...]

$\mathrm{Na}$ região do semiárido, onde se encontram os municípios influenciados direta e indiretamente pelo empreendimento, as atividades agropecuárias ainda são as forças motrizes da economia. As propriedades onde se desenvolvem essas atividades, pequenas e configuradas pela subsistência, são geralmente exploradas além de seus limites e com pouca tecnologia, produzindo resultados pouco eficientes. (EIA, VOLUME III, p.264).”
\end{abstract}

Dentro deste marco analítico desenhado por uma territorialidade abstrata, existe ainda a questão do trabalho camponês, que é abordado sob o crivo da ausência de formalidade, ou seja, do padrão urbano de vínculo empregatício. Embora o estudo reconheça que $94 \%$ da população é economicamente ativa, na fala da consultoria nas três audiências o aumento da formalização dos vínculos foi tratado como um impacto positivo do projeto, "pois isso vai se refletir nos tributos", explica a consultora. Não se questiona, entretanto, a possível descaracterização do trabalho atualmente realizado, a subordinação dos trabalhadores e as demais conseqüências da transformação do trabalho em emprego.

"Bom, emprego é um impacto positivo", categoriza a consultoria ambiental. Com um tom assertivo, cria-se um pressuposto de que a afirmação é consensual, inibindo os horizontes de problematização e reduzindo a geração destes postos de trabalho a uma simplificação unidimensional. Trata-se de um desdobramento da doxa do desenvolvimento.

O último elemento analisado será aquele que tange à definição da área atingida pelo projeto. A legislação não prevê uma definição para área de influência, tampouco estabelece procedimentos metodológicos para esta caracterização. Entretanto, a normatização do Conama oferece alguns critérios que devem ser observados. Dentre eles, a Resolução 01/86, define, no 


\section{Análise das estratégias metodológicas e discursivas do diagnóstico socioeconômico no estudo de impacto ambiental do projeto Santa Quitéria/Ceará}

artigo $1^{\circ}$, impacto ambiental e em seu artigo $5^{\circ}$, inciso III, prever que a definição dos limites a serem direta ou indiretamente atingidos, a área de influência do empreendimento, deve considerar a bacia hidrográfica no qual ele está inserido.

Este cenário vem gerando inúmeros problemas nos licenciamentos ambientais brasileiros, o que motivou o Ministério Publico Federal, por meio de sua $4^{\mathrm{a}}$ Câmara de Coordenação Câmara de Meio Ambiente e Patrimônio Cultural, a emitir a Nota Técnica nº. 39/2007, que procura sedimentar alguns pontos sobre o assunto, com o objetivo de facilitar a metodologia na definição destas áreas, o estabelecimento da competência dos órgãos ambientais e a participação dos sujeitos sociais atingidos pelo empreendimento. Segundo a Nota, estabelecer a definição das escalas temporais e espaciais dos eventos é fundamental pois, afinal, "quem decide as escalas de utilização tem o poder de admitir 'o que' ou 'quem' pertence ao fenômeno ou processo representado (NT nº. 39/2007 - $4^{\text {a }}$ CCR, p.10).

Paulo Afonso Leme Machado (2011) diz que, para definir a área de influência, é preciso observar vínculo indissociável entre ela e os impactos de um projeto (MACHADO, 2011, p. 242). Para a Agência Canadense de Avaliação Ambiental, mencionada na NT 39/2007 da $4^{a}$ CCR do MPF, impacto direto se compreende por aqueles em que a relação de causa-efeito não tem resultados intermediários. A nota firma, ainda, que "a cadeia de impactos nem sempre é evidente, pois decorre de como o sistema ambiental é examinado" (Nota Técnica nº 39/2007 - 4ª CCR) e que não há uma hierarquia entre os impactos diretos e indiretos. Conclui que o critério mais comum é a inclusão dos municípios envolvidos na bacia hidrográfica atingida.

No caso do Projeto Santa Quitéria, veja-se como o EIA caracterizou as áreas de influências (ARCADIS LOGOS, 2014, v.1, p. 375) e as críticas que foram tecidas. Foram identificadas como:

1. Área diretamente atingida (ADA): um raio de $10 \mathrm{~km}$ em torno do projeto, incluindo o distrito de Lagoa do Mato e os assentamentos de Morrinhos, Queimadas e Riacho das Pedras.

2. Área de influência direta quanto ao meio socioeconômico (AID): Municípios de Itatira e Santa Quitéria.

Revista de Direito Ambiental e Socioambientalismo | e-ISSN: 2525-9628 | Brasília | v. 3 | n. 1 | p. 40 60 | Jan/Jun. 2017. 
3. Área de influência indireta quanto ao meio socioeconômico (AII): Municípios de Canindé e Madalena.

4. Área de influência direta quanto ao meio físico-biótico (AID): Inclui a região compreendida pela sub-bacia do riacho Cunha-Moti, abarcando os divisores de águas das serras que ladeiam a Área Diretamente Afetada - ADA. Tem como limites: a norte, a crista da Serra do Céu; a leste, a Serra das Laranjeiras e a Serra do Quati; a sul, o divisor de águas do riacho Groaíras; a sul-sudoeste, o serrote Apapuá; a oeste, se estende pelo divisor de águas do riacho Cunha-Moti, margeando a serra do Gavião.

5. Área de influência indireta quanto ao meio físico-biótico (AII): Abrange as bacias hidrográficas da AID e o trecho a jusante da mesma, cuja área é formada pelas bacias do riacho Cunha-Moti, riacho dos Porcos e riacho dos Pintos, e parte da Bacia do rio Groaíras, delimitadas pelos divisores de águas dessas bacias com as bacias do riacho Jatobá e riacho dos Bois ao norte, e com as bacias do rio Groaíras, riacho do Frade e riacho do Cipó ao sul. Compreende também as respectivas unidades geológicas que abrigam os aquíferos presentes, com possibilidade de ocorrência de impactos negativos caso os eventuais processos de erosão, assoreamento e alteração da qualidade das águas superficiais e subterrâneas não sejam devidamente mitigados e controlados na AID.

As principais críticas referem-se a um subdimencionamento dos impactos e a invisibilização de comunidades do entorno da mina. Em relação ao subdimensionamento dos impactos, questiona-se a desconsideração de possíveis rotas de contaminação e fatores ambientais que podem ampliar o raio de impactos do projeto: a ação dos ventos na dispersão radionuclídeos e do gás radônio; poluição das águas e do solo, devendo-se considerar toda a rota dos rios acaraú, curú e banabuiú; poluição de lençóis freáticos; rejeitos radioativos nos produtos finais; o risco de acidentes durante o transporte de insumos e dos produtos finais, o que põe na rota de possível contaminação todo o percurso que liga o empreendimento até o Porto do Mucuripe, em Fortaleza/CE.

Em atendimento ao que dispõe a Resolução 01/86 do Conama, a área de influência deveria contemplar os municípios da Bacia do rio Acaraú, dentro da qual está o riacho Groaíras, diretamente atingido pelo empreendimento, mas diversos municípios foram excluídos. 
Durante as audiências públicas, entretanto, o foco do debate ocorreu diante da não inclusão de Fortaleza na área de influência indireta e, em maior grau, na invisibilidade de comunidades do entorno da mina.

Em relação à cidade de Fortaleza, apontou-se que como o escoamento da produção seria feito via Porto do Mucuripe ${ }^{15}$, a rota de transporte dos materiais perigosos deveriam estar inclusas nas áreas de influência do projeto, ademais quando se considera os riscos de vazamentos e acidentes.

Outra dimensão chamou atenção nos debates das audiências: a (in)visibilização de comunidades do entorno do projeto, que corresponde a uma interface entre as falhas na definição das áreas atingidas e na elaboração do diagnóstico social da região.

Conforme exposto, o EIA define a área diretamente atingida a partir de um raio de $10 \mathrm{~km}$ da mina e, apenas inclui e estuda os impactos para as comunidades de Morrinhos, Queimadas e Riacho das Pedras, e para o distrito de Lagoa do Mato. Nas audiências públicas, foram apontados de forma recorrente a ausência da inclusão do assentamento de Saco do Belém, o maior da região, e Tatajuba. Pesquisadores identificaram 156 localidades não registradas no EIA (MELO, 2015). A incompletude do estudo provocou reações e suspeitas sobre a lisura na condução do licenciamento ambiental.

\section{CONSIDERAÇÕES FINAIS}

Para as comunidades atingidas, as audiências públicas do projeto funcionaram como uma espécie de imagem desestabilizante, utilizando a analogia de Santos (2010, p.86), no sentido em que o contato direto com os discursos dos empreendedores, com a forma de abordagem e o silenciamento sobre comunidades e elementos que pertencem à região, estimularam a

\footnotetext{
${ }^{15}$ Segundo o EIA do projeto, "A expedição dos produtos será totalmente por via rodoviária, sendo o mercado consumidor formado basicamente pelos estados do nordeste, Tocantins e Pará, no caso dos fertilizantes e do fosfato bicálcico. No caso do concentrado de urânio, o mesmo será totalmente destinado para exportação pelo Porto de Fortaleza, também conhecido como Porto do Mucuripe, para processamento de "yellow cake" fora do país. Estão previstas para a utilização no escoamento de produtos as rodovias estaduais CE-366 e CE-456, e as rodovias federais BR- 020, BR-230, BR-135, BR-316, BR-266, BR-153, BR-122, BR-116 e BR-304. (EIA, Volume I, p. 131).”
} 
organização para o envolvimento da comunidade nas diversas discussões sobre o projeto. Após as audiências, uma moradora da região contou que ficava "muito revoltada com tudo isso que pode acontecer ao nosso redor porque eles só falam do Morrinhos, das Queimadas e do Riacho das Pedras, e nossas comunidade vizinha tá ficando tudo por fora”.

A caracterização realizada por meio do diagnóstico social, somada ao discurso da consultoria ambiental, demonstra um despreparo para a compreensão da territorialidade camponesa e as múltiplas dimensões das relações com o ambiente. As lacunas e equívocos metodológicos, o privilégio concedido ao ponto de vista dos gestores públicos e empreendedores, a afirmação de benefícios e a desconsideração das incertezas e críticas apontadas ao projeto são alguns dos traços marcantes do discurso que marca o Estudo de Impacto Ambiental.

Desta forma, o rito de análise dos impactos ambientais encontra-se incompleto diante da violação do dever de realizar um diagnóstico socioeconômico efetivamente capaz de visibilizar as teias sociais e produtivas que podem ser afetadas caso o projeto seja implementado. A implementação de parâmetros metodológicos para este diagnóstico, bem como para a definição das áreas direta e indiretamente atingidas, pode consistir em relevante contribuição do campo jurídico para a mitigação das inequidades consistentes nas análises de impactos ambientais.

\section{REFERÊNCIAS BIBLIOGRÁFICAS}

ACSERALD, Henri. Disputas cognitivas e exercício da capacidade crítica: o caso dos conflitos ambientais no Brasil. Revista Sociologias. Porto Alegre, ano 16, no 35, jan/abr 2014, p. 84-105.

ARAGÃO, Alexandra. Prevenção de riscos na União Europeia: o dever de tomar em consideração a vulnerabilidade social para uma protecção civil eficaz e justa. Revista Crítica de Ciências Sociais, 93 | 2011, 71-93.

ARCADIS LOGOS. Estudo de impacto ambiental projeto Santa Quitéria. São Paulo, 2014.

BENJAMIN, Antônio Herman. Direito Constitucional Ambiental Brasileiro. In: CANOTILHO, José Joaquim Gomes e MORATO LEITE, José Rubens (Orgs), Direito Constitucional Ambiental Brasileiro, 2 ed., São Paulo: Saraiva, 2008.

BOURDIEU, Pierre. O campo científico. Actes de Ia RechercheenSciences. Sociales, n. 2/3, jun. 1977, p. 88-104. Tradução de Paula Montero.

BRONZ, Deborah. Empreendimentos e empreendedores: formas de gestão, classificações e conflitos a partir do licenciamento ambiental, Brasil, século XXI. Tese de Doutorado.

Revista de Direito Ambiental e Socioambientalismo | e-ISSN: 2525-9628 | Brasília | v. 3 | n. 1 | p. 40 60 | Jan/Jun. 2017. 
Análise das estratégias metodológicas e discursivas do diagnóstico socioeconômico no estudo de impacto ambiental do projeto Santa Quitéria/Ceará

Universidade Federal do Rio de Janeiro. Programa de Pós-graduação em antropologia social. Rio de Janeiro, 2011.

CANOTILHO, J.José Gomes. Estado constitucional ecológico e democracia sustentada. In: Ferreira, Heline Sivini; Leite, José Rubens Morato (Orgs). Estado de direito ambiental: tendências, aspectos constitucionais e diagnósticos. Rio de Janeiro: Forense Universitária, 2004.

CARDOSO DE OLIVEIRA, Roberto. O trabalho do antropólogo: olhar, ouvir, escrever. Revista de Antropologia (USP), vol. 39, nº 1, São Paulo, 1996.

CARNEIRO, Jurandir Eder. Política Ambiental e a ideologia do desenvolvimento sustentável. In: ZHOURI, Andrea; LASCHEFSKI, Klemens; PEREIRA, Doralice Barros (Orgs). A insustentável leveza da política ambiental: Desenvolvimento e conflitos socioambientais. Belo Horizontes: Autêntica, 2005.

ECKERT, Cornelia; ROCHA, Ana Luiza Carvalho. Etnografia: saberes e práticas. In: PINTO, Céli Regina Jardim e GUAZZELLI, Augusto Barcellos. Ciências Humanas: pesquisa e método. Porto Alegre: Editora da Universidade, 2008.

INCRA. Painel dos Assentamentos. Disponível em <http://painel.incra. gov.br/ sistemas/index.php>, acesso realizado em 08.08.2015.

Instituto de Desenvolvimento do Estado do Ceará - IDACE. Disponível em <http://www.idace.ce.gov.br/sitio/index.php/categoria-o-idace?Cssfile=principal.css>, acesso realizado em 17.07.2015.

MACHADO, Paulo Afondo Leme. Direito Ambiental Brasileiro, 19 ed., São Paulo: Malheiros Editores, 2011.

MAGNANI, José Guilherme Cantor. De perto e de dentro: notas para uma etnografia urbana. Revista Brasileira de Ciências Sociais. V. 17, n. 49, 2002.

MEIRELES, Antonio Jeovah; CASSOLA, Rodrigo s; TUPINAMBÁ, Soraya Vanini; QUEIROZ, Luciana de Souza. IMPACTOS AMBIENTAIS DECORRENTES DAS ATIVIDADES DA CARCINICULTURA AO LONGO DO LITORAL CEARENSE, NORDESTE DO BRASIL. Mercator - Revista de Geografia da UFC, ano 06, número 12, 2007.

MELO, Rafael Dias. Riscos Ambientais e Processos de Vulnerabilização: diálogos e controvérsias em torno do Projeto de Mineração de Urânio e Fosfato em Santa Quitéria, Ceará. Dissertação (Mestrado em Desenvolvimento e Meio Ambiente) - Universidade Federal do Ceará. Fortaleza: UFC, 2015.

MILANEZ, B. ; SANTOS, R. S. P. . Neodesenvolvimentismo e neoextrativismo: duas faces da mesma moeda?. In: 37o. Encontro Anual da ANPOCS, 2013, Águas de Lindóia. Anais do 37o. Encontro Anual da ANPOCS, 2013

MINISTÉRIO PÚBLICO FEDERAL. Nota Técnica 39/2007 - 4a CCR. Disponível em <http://www.mpf.mp.br/atuacao-tematica/ccr4/dados-da-atuacao/grupos-de-trabalho/gt-

Revista de Direito Ambiental e Socioambientalismo | e-ISSN: 2525-9628 | Brasília | v. 3 | n. 1 | p. 40 60 | Jan/Jun. 2017. 
licenciamento/documentos-diversos/informa-tecnicas/NT\%20039-

07_Encaminha_trabalho_area_de_influencia.pdf>, acesso realizado em 20.05.2017.

MONTEZUMA, T. F. P. F. Licenciar e Silenciar: análise do conflito ambiental nas audiências públicas do Projeto Santa Quitéria, CE. Dissertação (Mestrado em Direito) - Universidade Federal do Ceará. Fortaleza: UFC, 2015.

RIGOTTO, R M; O "progresso" chegou. E agora? As tramas da (in)sustentabilidade e a sustentação simbólica do desenvolvimento. Tese de Doutorado. Programa de Pós Graduação em Ciências Sociais. Universidade Federal do Ceará, 2004.

. et al. Agrotóxicos, trabalho e saúde - vulnerabilidade e resistência no contexto da modernização agrícola do Baixo Jaguaribe, Ceará. $1^{\mathrm{a}}$ Ed. Fortaleza: Editora UFC e Coedição Expressão Popular, 2011.

SAMPAIO JR., Plínio de Arruda. Desenvolvimentismo e neodesenvolvimentismo: tragédia e farsa. Revista Serv. Soc. Soc., São Paulo, n. 112, 2012, out./dez, p. 672-688.

SANTOS, Boaventura de Sousa. A gramática do tempo: para uma nova cultura política. 3 ed. São Paulo: Cortez, 2010.

SILVA, Maria de Lourdes Vicente. As Repercussões do Processo de Des-re-territorialização Empreendido pela Modernização Agrícola sobre o Ambiente, o Trabalho e a Saúde de Mulheres Camponesas na Chapada do Apodi/CE. Dissertação de Mestrado. Programa de Pós Graduação em Desenvolvimento e Meio Ambiente. Universidade Federal do Ceará.

ZHOURI, Andrea; LASCHEFSKI, Klemens. Conflitos ambientais. Publicação do Grupo de Estudos em Temáticas Ambientais da Universidade Federal de Minas Gerais - GESTA/UFMG, 2010 . 